\title{
Electrical Resistivity of Fly Ash Blended Cement Paste at Hardening Stage
}

\author{
İlker Bekir TOPÇU ${ }^{1}$, Tayfun UYGUNOĞLU ${ }^{2}$, İsmail HOCAOĞLU ${ }^{1}$ * \\ ${ }^{1}$ Eskişehir Osmangazi University, Engineering Faculty, Civil Engineering Department, 26480, Eskişehir, Turkey \\ ${ }^{2}$ Afyon Kocatepe University, Engineering Faculty, Civil Engineering Department, 03200, Afyonkarahisar, Turkey

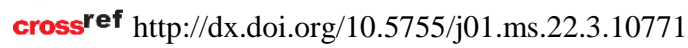

Received 20 March 2015; accepted 17 May 2015

In this study, the effects of fly ash on the electrical resistivity of hardening (setting) cement paste were investigated. Different combinations of water/binder ratio and binder dosage levels were prepared for the mixtures. The fly ash was used in the mixtures by replacing the cement in ratio of $0 \%, 10 \%, 20 \%$ and $30 \%$ by weight. The measurements were done at room temperature. The relation between electrical resistivity and hydration time with and without electric current application was investigated. The results obtained indicate the influence of fly ash content and water to binder ratio on the electrical resistivity of all the pastes under investigation. As a result, electric current application can be used on the cement paste with high volume fly ash in order to accelerate curing period.

Keywords: cement paste, electrical resistivity, fly ash, hydration time.

\section{INTRODUCTION}

The use of fly ash in the concrete production has gained prominence in global concrete construction. In general, the pozzolanic reaction is slow, so strength development and heat of hydration is low [1]. These cause some problems such as later de-moulding. On the other hand, pozzolanic reactions can be accelerated through increasing the temperature.

In monitoring of the whole hardening process of a cement paste, electrical resistivity can be used as a parameter $[2,3]$. Electrical conductivity process occurs primarily due to the ion transport through the pore solution in a cement-based system and it is a crucial parameter to study the hydration process of cement pastes at early stages $[4,5]$. During the hydration of cement paste after mixing, calcium $(\mathrm{Ca})$ and hydroxyl $(\mathrm{OH})$ ions go into solution within the first ten minutes [6]. After that, little happens except for a slow precipitation of semi-crystalline calcium silicate hydrate gel (C-S-H) while the calcium and hydroxyl ion concentrations go on increasing slowly [7, 8]. The degree of hydration describes the process of hydration, and directly relates to the fraction of the hydration products or porous structure in a hydration system in cement-based materials [9]. The variation of conductivity as function of time can indeed reflect internal changes of the pore solution of cement paste with time [10]. As it is well-known, the hydration process in cement paste results in the formation of $\mathrm{C}-\mathrm{S}-\mathrm{H}$, calcium $\mathrm{CH}$, ettringite and other compounds. During hydration, the capillary pores in hardening cement paste are gradually filled up with hydration products and the solid phases form a rigid microstructure with increasing strength. Then, electrical resistivity of cement paste increases with time [11].

Xiao et al. used electrical resistivity for measurement and Marsh cone for provide a quick way to evaluate and select suitable superplasticizer in concrete. In another study,
Xiao et al. [12] measured the electrical resistivity of the concrete mixes and the pore solution within the mixes by a non-contact electrical resistivity apparatus. They declared that electrical resistivity measurement reflects the hydration kinetics of fresh concrete. Chung [13] made research about the use of electrical resistance measurement to monitor damage in cement-based materials. Damage is demonstrated as through an increase in the resistivity. In order to identify the damage in the cement-based material, the volume resistivity can be used as a quantity. It is concluded that the volume resistivity can be enhanced due to the damage. Tamaás et al. [14] have shown that the time dependence of the electrical response of cement pastes is complex and influenced by a number of variables such as water content, temperature, clinker fineness, gypsum and additive content.

There are some articles have been published on various aspects of electrical measurement of setting and hardened cement paste. Therefore, this work aimed to study the electrical resistivity of blended cement pastes containing different types of fly ash (FA), from 0 to 30 mass $\%$ and different water/binder ratios $(0.40,0.45,0.50,0.55)$.

\section{EXPERIMENTAL DETAILS}

The cement paste mixes investigated in this study were prepared with Ordinary Portland cement (OPC) of CEM I/42.5 R, produced according to the European Standards EN 197-1 [15], Cement (OPC) and fly ash (FA) are demonstrated in Fig. 1. The physical and chemical properties of OPC and fly ash are presented in Table 1. The particle size distribution of OPC and fly ash were also given in Fig. 2. The main components of OPC are in the proportions of $60.11 \%, 11.02 \%, 6.97 \%$ and $9.95 \%$ for $\mathrm{C}_{3} \mathrm{~S}, \mathrm{C}_{2} \mathrm{~S}, \mathrm{C}_{3} \mathrm{~A}$ and $\mathrm{C}_{4} \mathrm{AF}$, respectively. OPC has initial setting time of $182 \mathrm{~min}$ and final setting time of $310 \mathrm{~min}$.

\footnotetext{
* Corresponding author. Tel.: +90-272-2133330; fax: +90-272-2133330.

E-mail address: afyonbeton@hotmail.com (I. Hocaoglu)
} 


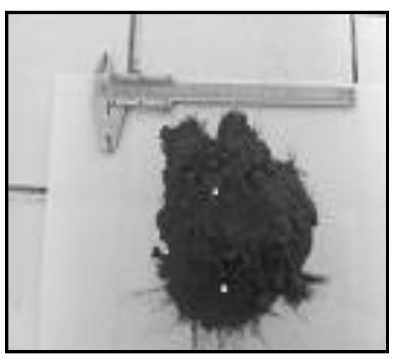

Cement

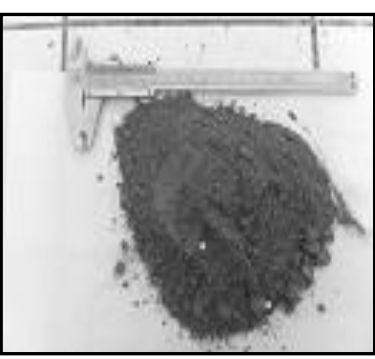

Fly ash
Fig. 1. A view of OPC and fly ash additives

Table 1. Physical and chemical properties of OPC and fly ash additives

\begin{tabular}{|c|c|c|}
\hline Component, \% & $\mathrm{OPC}$ & FA \\
\hline $\mathrm{CaO}$ & 63.6 & 6.66 \\
\hline $\mathrm{SiO}_{2}$ & 19.6 & 47.4 \\
\hline $\mathrm{Al}_{2} \mathrm{O}_{3}$ & 4.72 & 19.8 \\
\hline $\mathrm{Fe}_{2} \mathrm{O}_{3}$ & 3.27 & 11.8 \\
\hline $\mathrm{MgO}$ & 1.91 & 4.76 \\
\hline $\mathrm{Na}_{2} \mathrm{O}$ & 0.34 & 0.57 \\
\hline $\mathrm{K}_{2} \mathrm{O}$ & 1.06 & 2.62 \\
\hline $\mathrm{SO}_{3}$ & 4.72 & 1.86 \\
\hline $\mathrm{Cr}_{2} \mathrm{O}_{3}$ & 0.04 & 0.13 \\
\hline $\mathrm{TiO}_{2}$ & 0.41 & 0.88 \\
\hline LOI & 2.69 & 2.76 \\
\hline Specific gravity & 3.07 & 1.99 \\
\hline Fineness, $\mathrm{cm}^{2} / \mathrm{g}$ & 3312 & 3126 \\
\hline
\end{tabular}

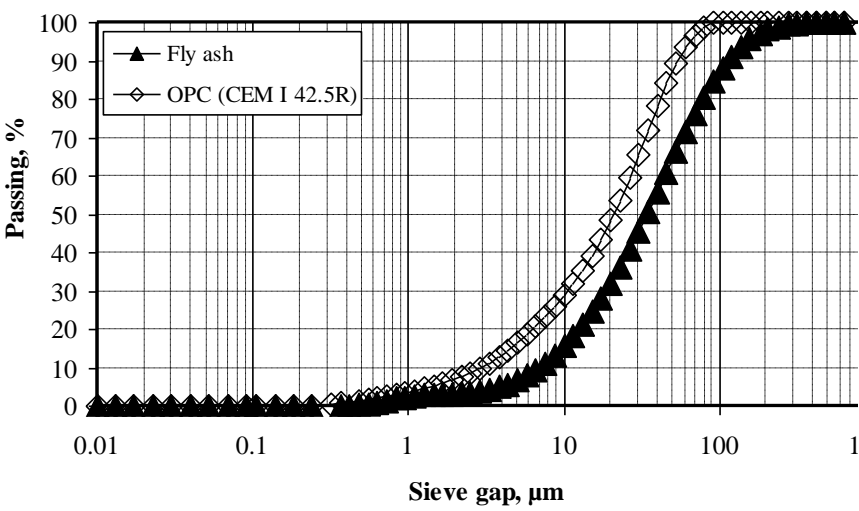

Fig. 2. Particle size distribution of OPC and fly ash

\subsection{Cement paste mixes for electrical resistivity}

The cement paste mixes were proportioned by replacing cement with fly ash in ratios of $0 \%$ (control), $10 \%, 20 \%$ and $30 \%$ (by weight of cement). The mixtures used in the study were also proportioned in water to binder $(\mathrm{w} / \mathrm{b})$ ratios of $0.40,0.45,0.50$ and 0.55 . The cement, water, and fly ash were mixed in the mixer for 5 min.

Apart from setting time measurements, following cement paste mixing, it was poured into insulated of electricity moulds that in size of $40 \times 40 \times 160 \mathrm{~mm}$. After pouring the mix into oiled wooden molds, an external vibrator was used to facilitate compaction and decrease the amount of air bubbles. Copper plates were embedded to both ends of the setting cement paste in the mold. DC current was applied with a $15 \mathrm{~V}$ voltage to cupper plates during $24 \mathrm{~h}$. In every $2 \mathrm{~min}$, the current was measured and reported with an ampere meter. The measurements were done at room temperature. In the experimental setup, four same molds were used the same time, and the data collection was carried out by a data logger. The electrical resistivity (R) of each setting cement paste was calculated as follows.

$R=\frac{A}{1} \times \frac{U}{I}$,

where 1 is the distance between the voltage electrodes; $A$ is the cross-sectional area of the sample; $I$ is the current through the sample; and $U$ is the voltage drop over the electrodes.

\section{RESULTS AND DISCUSSION}

\subsection{Effect of fly ash and content on electrical current}

The conductor between two electrodes in cement paste mixture was initially the water in the mixture which is in the liquid phase. At the beginning, all the pores in the mixture have connections among themselves. Therefore, the electrolysis between the electrodes has arisen from the free water of these pores. However, hydrated products occur in the course of time because of the reaction of the main components in the cement paste with water, and the pores which were once connected to each other have been separated. Accordingly, electrical resistivity of cement paste increase in time and when the cement completes its hardening time, its electrical resistivity amount reaches the maximum value. Consequently, the electrical resistivity of cement is directly associated with the hydration of the cement.

The cement paste having different water/binder proportions without any additives and the cement paste having different fly ash proportions have been investigated during the time until the setting time of the cement paste has taken (one day at the laboratory having suitable conditions).

The conduct of electrical current on the cement paste without any mineral additives is directly associated with water/binder proportion of the additive. This experiment shows almost the same at the beginning. Due to the electrical conductivity of water, it can be seen in Fig. 3 a that the cement paste which has higher proportion of water/binder conducts much more electrical current. When the electrical conductivities of the cement pastes without any mineral additives whose water/binder proportions are 0.55 and 0.40 , respectively, at the initial phase, are compared with each other, it has been concluded that the cement paste whose water/binder proportion is 0.55 is almost $17 \%$ more conductive than the cement paste whose water/binder proportion is 0.40 .

When the fly ash as a mineral additive is added to the cement paste, its electrical conductivity proportion is less than the cement paste without any mineral additive. (Fig. $3 \mathrm{~b}-\mathrm{d}$ ). Enhancing the fly ash proportion in the additive, which has been added instead of cement, causes the cement paste's conducting less current. It can be reached this conclusion from Fig. $3 \mathrm{~b}-$ d. It has been measured that at the initial phase, the electrical conductivities of cement pastes, whose water/binder ratio is 0.55 and in which fly ash has been added in the proportions of $10 \%, 20 \%$ and $30 \%$, respectively instead of being added cement, are $124 \mathrm{~mA}$, $77 \mathrm{~mA}$ and $26 \mathrm{~mA}$, respectively (Fig. $3 \mathrm{a}-\mathrm{d}$ ).

When the fly ash added to the cement paste is being increased, the electrical resistivity has increased. The reason of this is the decrease of water content in the additive. 
Therefore, it can be concluded that when the fly ash proportion is increased, the water in the cement paste reacts chemically faster with the fly ash and the additive with the fly ash hardens faster than the additive without the fly ash.

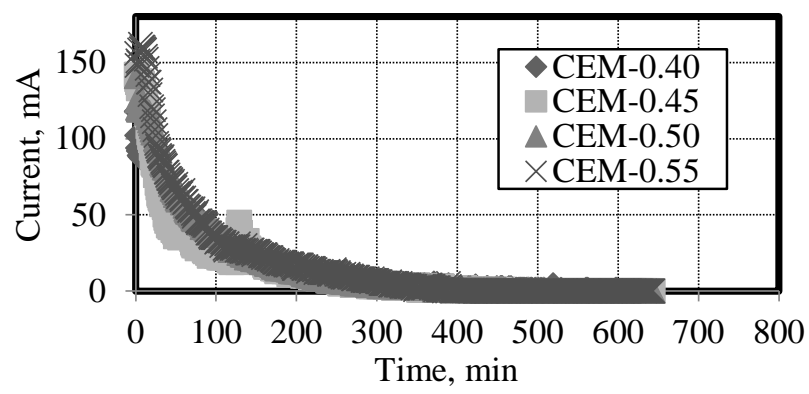

a
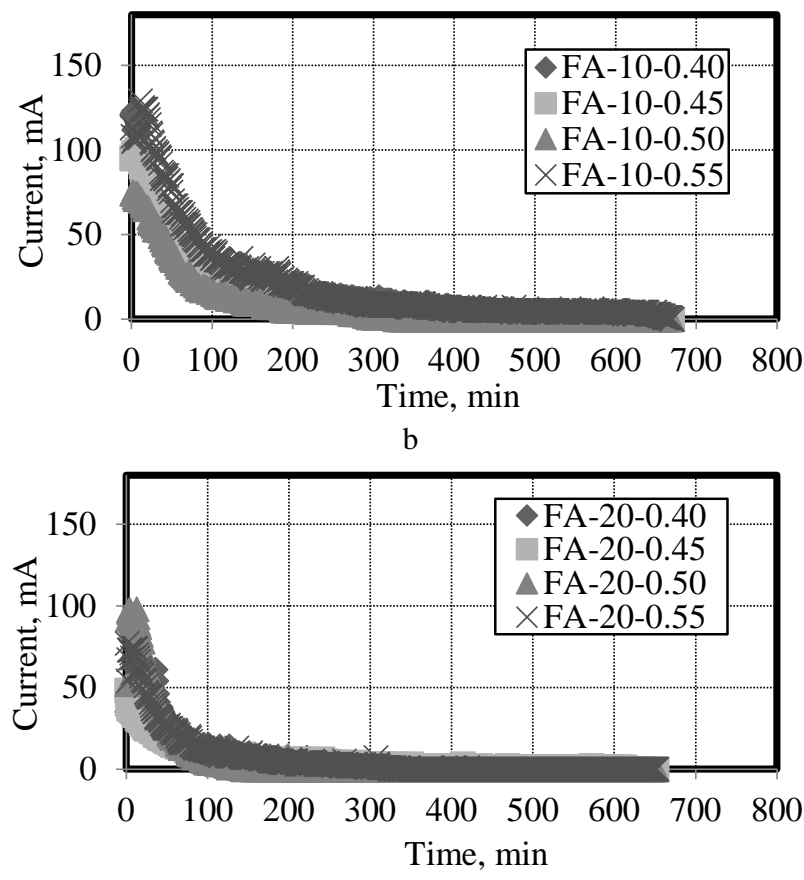

c

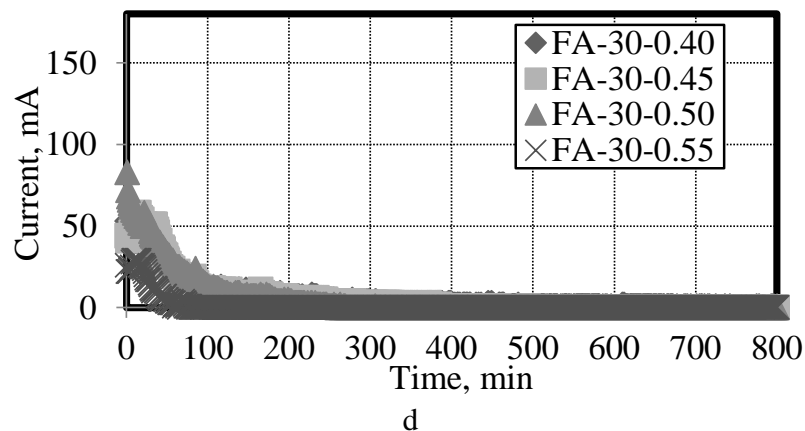

Fig. 3. Electrical current change in cement paste with both different ratio of $\mathrm{w} / \mathrm{b}$ and fly ash: $\mathrm{a}-0 \% ; \mathrm{b}-10 \%$; $c-20 \% ; d-30 \%$

\subsection{Effect of fly ash and content on electrical resistivity}

In Fig. 4 , as a result of replacing FA with the cement in specific proportions by weight, the electrical resistivity of binder cement paste in fresh state, which depends on the hydration time, has been observed. Besides, different waterbinder ratios have been used for fly ash. The lower resistivity values were obtained on the blends having higher
OPC contents, during the initial stage of hydration for the each water to binder ratio. In general, the resistivity values increased sharply with a notable appearance located between 10 and 100 min for the pastes. During the initial stage of hydration time, the resistivity takes the lowest value as a result of the hydrolysis of the OPC components. In other words, the charge carrier are realized by $\mathrm{Ca}^{+2}, \mathrm{OH}^{-}, \mathrm{SO}_{4}^{-2}$, and alkali ions [16]. Once the concentration of these ions in the cement paste becomes very high, ionic association starts. As a result of this ionic association, the electrical resistivity is increased Fig. 4.

The results of Fig. 4 show also the effect of different FA additive content on the electrical resistivity values of the blended cement pastes. For 10-30 min. of hydration span, the rate of the electrical resistivity of FA has risen collaboration with enhancing the FA additive ratio from $0 \%$ to $30 \%$. When the impact of the additive having different proportions $(10 \%, 20 \%, 30 \%)$ of fly ash on the electrical resistivity has been examined, the most effective additive on the rise of the electrical resistivity consists of $30 \%$ of fly ash. As it has been mentioned before, the rise of the electrical resistivity is an indicator for hardening of the cement paste. However, when the electric current is conducted through the additives, the cement starts to harden in less time in comparison with the control mixture. This situation can easily be recognized due to the increase of the electrical resistivity.

The electrical resistivity value is an indication of hydration. With the help of being conducted electric current through mixtures with fly ash, hydration is occurred in less time. In other words, the curing period has become faster.

Consequently, electrical resistivity behaviour of blended cement paste composites can be greatly modified by the use of fly ash. Furthermore, the hydration duration of cement paste with FA additives can be accelerated as a result of conducting electric current.

This result is mainly attributed to some factors, namely; the decrease in the number of leaching ions during the hydration of OPC as its proportion decreases in the mixes. The degree of consumption of free $\mathrm{Ca}(\mathrm{OH})_{2}$ released as a result of OPC hydration leading to the formation of poorly crystallized calcium silicate hydrates during the hydration of OPC increased as the pozzolanic mineral additive FA content increases $[16,17]$. On the other hand the advance of time of hydration of all mixtures decreased electrical resistance Fig. 4. Due to the mixtures containing high amounts of fly ash additives, the electrical resistivity enhances Fig. $4 \mathrm{~d}$. The hydration interaction between pozzolanic mineral additives (with high $\mathrm{SiO}_{2}+\mathrm{Al}_{2} \mathrm{O}_{3}+\mathrm{Fe}_{2} \mathrm{O}_{3}$ ) and the free $\mathrm{Ca}(\mathrm{OH})_{2}$ released to form $\mathrm{C}-\mathrm{S}-\mathrm{H}$ results in a decrease in the free water content of the paste leading to a sort of acceleration of the ettringitemonosulfate transformation [18, 19]. For this reason adding the fly ash to the blend makes the electrical resistivity increased Fig. 4. An interaction between fly ash grains and the initially formed $\mathrm{Ca}(\mathrm{OH})_{2}$ takes place that is leading to a further decrease in the $\mathrm{Ca}(\mathrm{OH})_{2}$ content of the initially formed C-S-H with increasing duration of hydration time. The C-S-H is thus produced as a result of hydration interaction between the initially formed hydrates and the unhydrated parts of fly ash grains [19-21]. Sudden heigher of electrical resistivity related to hydration time is a clear 
proof of this case. So, an accelerated cure for cement paste can be made by using both fly ash and electric current.
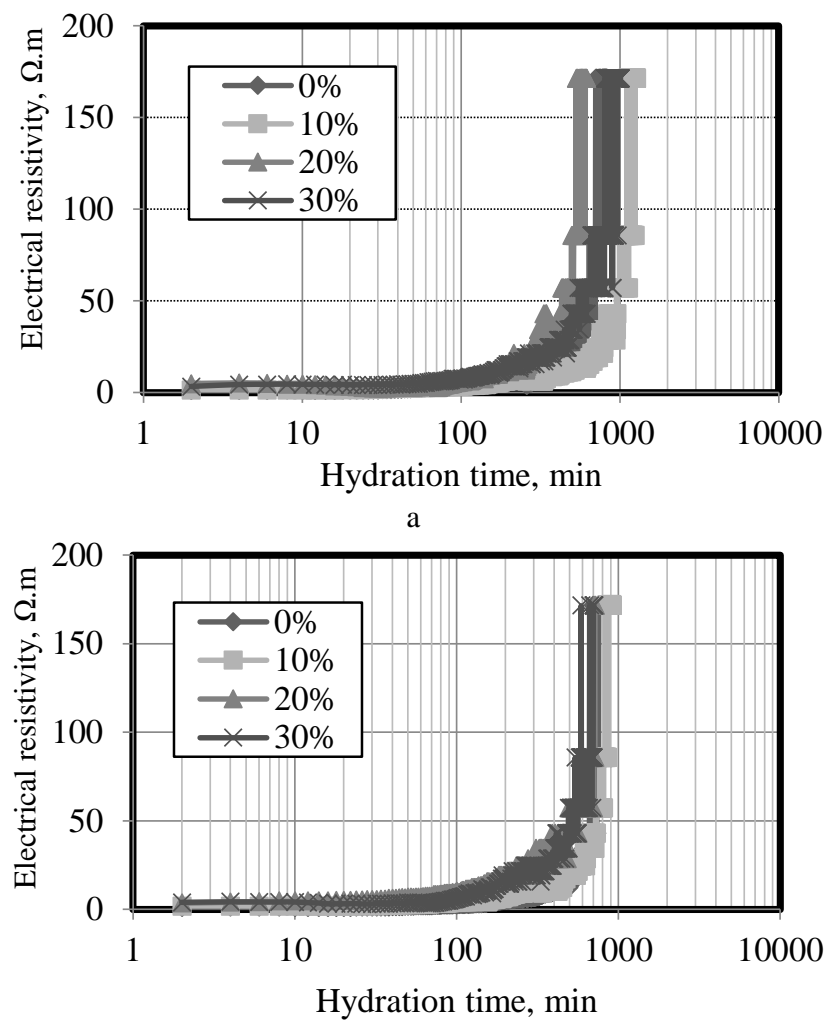

b

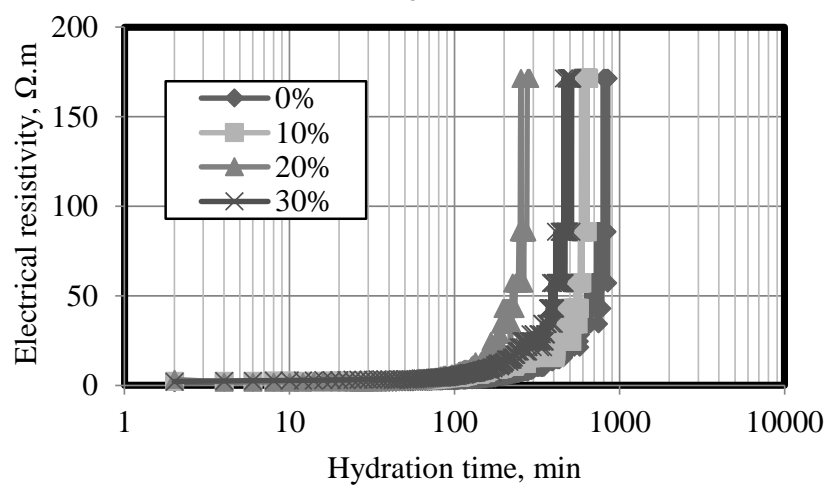

$\mathrm{c}$

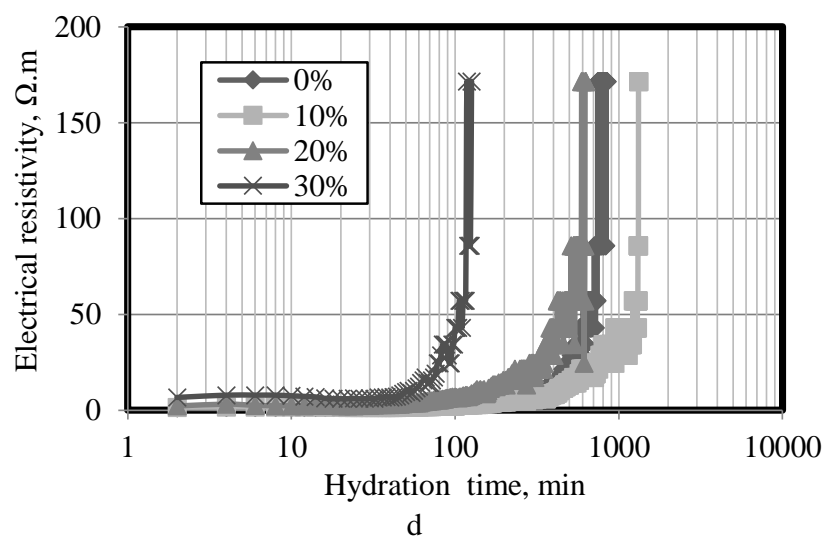

Fig. 4. Electrical resistivity of cement paste with fly ash in ratio of water/binder: $a-0.4 ; b-0.45 ; c-0.50 ; d-0.55$

\subsection{Effect of water to binder ratio}

When the additive which includes fly ash is considered, when cement paste is in liquid phase, in another words when it is on the hydration stage of which electric current is easily conducted, by increasing water and binder amounts, electrical resistivity is risen. Free space water which is in the gaps of the mixture is used in chemical reactions for producing hydration products and in hydrolysis for conducting electric current. Therefore, by increasing water and binder amount, hydrolysis reaction is accelerated. A high water to binder ratio leads to a greater ability to conduct electricity of blended cement paste [22].

\section{CONCLUSIONS}

In the present study, the effects of fly-ash and water to binder ratio on the electrical resistivity of cement pastes were studied. Several conclusions can be drawn from this study:

1. Depending upon the hydration time, while the electrical resistivity in low water/binder ratio increases suddenly, the increase speed of the high water/binder ratio is slower.

2. Because of its pozzolanic feature, the fly ash increases the electrical resistivity of cement paste at hardening stage.

3. When the fly ash added to the cement paste is being increased, the electrical resistivity has also increased.

4. The electrical resistivity has increased by the increasing of the fly ash additive content and this situation has occurred during the less hydration time.

5. The electrical resistivity value can be evaluated as an indication of hydration. With the help of being applied electric current to the mixtures with fly ash, hydration is occurred in less time. In other words, the curing period has become faster.

6. Different water-binder ratios have been used for fly ash. The lower resistivity values were obtained on the blends having higher OPC contents, during the initial stage of hydration for the each water to binder ratio. However, the cement paste which has higher proportion of water/binder conducts much more electrical current. Consequently, electrical resistivity behavior of blended cement paste composites can be greatly modified by the use of fly ash additives. Furthermore, the hydration duration of cement paste with fly ash additives can be accelerated as a result of applying electric current.

\section{REFERENCES}

1. Morsy, M.S. Effect of Temperature on Electrical Conductivity of Blended Cement Pastes Cement and Concrete Research 29 1999: pp. 603-606.

2. Backe, K.R., Lile, O.B., Lyomov, S.K. Characterizing Curing Cement Slurries by Electrical Conductivity SPE Drilling \& Completion 2001: pp. $201-207$.

3. Whittington, H.W., McCart, J., Forde, M.C. The Conduction of Electricity through Concrete Magazine of Concrete Research 33 1981: pp. $48-60$. http://dx.doi.org/10.1680/macr.1981.33.114.48

4. Xiao, L., Li, Z., Wei, X. Selection of Superplasticizer in Concrete Mix Design by Measuring the Early Electrical Resistivities of Pastes Cement and Concrete Composites 29 2007: pp. $350-356$. 
5. Schwarz, N., DuBois, M., Neithalath, N. Electrical Conductivity Based Characterization of Plain and Coarse Glass Powder Modified Cement Pastes Cement and Concrete Composites 29 2007: pp. 656-666.

6. Wei, X., Li, Z. Early Hydration Process of Portland Cement Paste by Electrical Measurement Journal of Materials in Civil Engineering 18(1) 2006: pp. $99-105$.

7. Buenfeld, N.R., Newman, J.B. Examination of Three Methods for Studying Ion Diffusion in Cement Pastes, Mortars, and Concrete Materials and Structures 20 1987: pp. 3-10.

8. Li, Z., Xiao, L., Wei, X. Determination of Concrete Setting Time Using Electrical Resistivity Measurement Journal of Materials in Civil Engineering 19 (5) 2007: pp. 423-427.

9. Levita, G., Marchetti, A., Gallone, G., Princigallo, A., Guerrini, G.L. Electrical Properties of Fluidified Portland Cement Mixes in the Early Stage of Hydration Cement and Concrete Research 30 2000: pp. 923-930.

10. Rajabipour, F., Weiss, J. Electrical Conductivity of Drying Cement Paste Materials and Structures 40 2007: pp. $1143-1160$.

11. Koleva, D.A., Copuroglu, O., Breugel, K.V., Ye, G., Wit, J.H.W. Electrical Resistivity and Microstructural Properties of Concrete Materials in Conditions of Current Flow Cement and Concrete Composites 30 2008: pp. $731-744$.

12. Xiao, L., Li, Z. Early-age Hydration of Fresh Concrete Monitored by Non-Contact Electrical Resistivity Measurement Cement and Concrete Research 38 2008: pp. $312-319$. http://dx.doi.org/10.1016/j.cemconres.2007.09.027

13. Chung, D.D.L.R. Damage in Cement-Based Materials, Studied by Electrical Resistance Measurement Materials Science and Engineering 42 2003: pp. 1-40.
14. Tamaás, F.D., Farkas, E., Vörös, M., Roy, D.M. LowFrequency Electrical Conductivity of Cement, Clinker and Clinker Mineral Pastes Cement and Concrete Research 17 1987: pp. $340-348$. http://dx.doi.org/10.1016/0008-8846(87)90116-5

15. EN 197-1/A3, Cement- Part 1: Compositions and Conformity Criteria for Common Cements. TSE, Ankara, Turkey: 2010 [in Turkish].

16. Salem, T.M. Electrical Conductivity and Rheological Properties of Ordinary Portland Cement-Silica Fume and Calcium Hydroxide-Silica Fume Pastes Cement and Concrete Research 32 2002: pp. 1473-1481. http://dx.doi.org/10.1016/S0008-8846(02)00809-8

17. McCarter, W.J., Starrs, G., Chrisp, T.M. Electrical Conductivity, Diffusion, and Permeability of Portland Cement-Based Mortars Cement and Concrete Research 30 2000: pp. $1395-1400$. http://dx.doi.org/10.1016/S0008-8846(00)00281-7

18. Billberg, P. Effect of Mineral and Chemical Admixtures on Fine Mortar Rheology American Concrete Institute SP 173 1997: pp. $301-320$.

19. Abo-El-Enein, S.A., Abou-Gamra, Z.M., El-Hosiny, F.I., El-Gamal, S.M.A. Characteristics of $\mathrm{Ca}(\mathrm{OH})_{2}$-Silica Fume Mixtures Journal of Thermal Analysis 46 1996: pp. $275-284$ http://dx.doi.org/10.1007/BF01979967

20. Wei, X., Li, Z. Study on Hydration of Portland Cement with Fly Ash Using Electrical Measurement Materials and Structures 38 2005: pp. 411-417.

21. Ay, N., Topçu, I.B. The Influence of Silicoferrochromium Fume on Concrete Properties Cement and Concrete Research 25 1995: pp. 387-394.

22. Heikal, M., Morsy, M.S. Aiad, I. Effect of Treatment Temperature on the Early Hydration Characteristics of Superplasticized Silica Fume Blended Cement Pastes Cement and Concrete Research 35 2005: pp. 680-687. 